\title{
II.2. \\ Gastrine et cancers du colon
}

B. MONGES

Marseille

La gastrine a un rôle trophique sur la muqueuse digestive et sur les lignées de cellules de cancers coliques en culture. L'utilisation du PROGLUMIDE, antagoniste des récepteurs de la gastrine, sur une lignée d'un cancer colique humain (Caco-2), provoque une diminution de la prolifération cellulaire (* A 356). Ceci suggère la possibilité d'une sécrétion autocrine de gastrine par cette lignée cellulaire.

Des travaux précédents avaient montré qu'une hypergastrinémie était fréquemment retrouvée au cours des cancers du colon. Deux séries (* A 372 et * A 375) apportent des résultats discordants en ne retrouvant aucune élévation de la gastrinémie au cours de cette pathologie. 